\title{
Cooperative effects in differentiation and proliferation between PDGF-BB and matrix derived synthetic peptides in human osteoblasts
}

\author{
Thomas Vordemvenne ${ }^{1 *}$, Jürgen RJ Paletta ${ }^{2}$, Rene Hartensuer ${ }^{1}$, Thomas Pap ${ }^{3}$, Michael J Raschke ${ }^{1}$ and \\ Sabine Ochman ${ }^{1}$
}

\begin{abstract}
Background: Enhancing osteogenic capabilities of bone matrix for the treatment of fractures and segmental defects using growth factors is an active area of research. Recently, synthetic peptides like AC-100, TP508 or p-15 corresponding to biologically active sequences of matrix proteins have been proven to stimulate bone formation. The platelet-derived growth factor (PDGF) BB has been identified as an important paracrine factor in early bone healing. We hypothesized that the combined use of PDGF-BB with synthetic peptides could result in an increase in proliferation and calcification of osteoblast-like cells.
\end{abstract}

Methods: Osteoblast-like cell cultures were treated with PDGF and synthetic peptides, singly and as combinations, and compared to non-treated control cell cultures. The cultures were evaluated at days 2, 5, and 10 in terms of cell proliferation, calcification and gene expression of alkaline phosphate, collagen I and osteocalcin.

Results: Experimental findings revealed that the addition of PDGF, p-15 and TP508 and combinations of PDGF/AC-100, PDGF/p-15 and PDGF/TP508 resulted in an increase in proliferating osteoblasts, especially in the first 5 days of cultivation. Proliferation did not significantly differ between single factors and factor combinations $(p>0.05)$. The onset of calcification in osteoblasts occurred earlier and was more distinct compared to the corresponding control or PDGF stimulation alone. Significant difference was found for the combined use of PDGF/p-15 and PDGF/AC-100 ( $p<0.05)$.

Conclusions: Our findings indicate that PDGF exhibits cooperative effects with synthetic peptides in differentiation and proliferation. These cooperative effects cause a significant early calcification of osteoblast-like cells $(p<0.05)$. We suggest the combination of synthetic peptides and PDGF as a potential clinical approach for accelerating bone healing or coating osteosynthesis materials.

\section{Background}

Enhancing the osteogenic capabilities of bone matrix for the treatment of fractures and segmental bone defects is an active area of research. It is well-known that the use of oligopeptides or growth factors promotes osteogenic cell proliferation and differentiation in vitro and in vivo [1-4]. There are many different pathways in research to address the acceleration of fracture healing.

The platelet-derived growth factor (PDGF), a paracrine factor in fracture hematoma, has proven its efficacy in

\footnotetext{
* Correspondence: thomas.vordemvenne@ukmuenster.de 'Department of Trauma, Hand and Reconstructive Surgery, University Hospital Münster, Germany

Full list of author information is available at the end of the article
}

early bone healing $[5,6]$. It is a homodimeric or heterodimeric protein with $\mathrm{A}$ and $\mathrm{B}$ polypeptide chains that has three possible isoforms: PDGF-AA, PDGF-BB and PDGF$A B$ [7]. PDGF is a heat-stable, positively charged protein produced by osteoblasts, platelets and monocytes/macrophages. PDGF-B has higher mitogenic and chemotactic potential and also a higher affinity to bone matrix than PDGF-A [8]. Although it is established that bone cells produce and respond to PDGF-B [9], the role of this factor in the healing of fractures has not been fully defined. PDGFB staining was detected in macrophages and in some primitive mesenchymal cells around the hematoma on day 3 after the fracture. These findings support the hypothesis

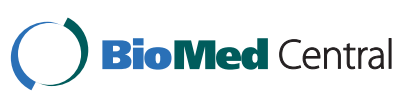

(c) 2011 Vordemvenne et al; licensee BioMed Central Ltd. This is an Open Access article distributed under the terms of the Creative Commons Attribution License (http://creativecommons.org/licenses/by/2.0), which permits unrestricted use, distribution, and reproduction in any medium, provided the original work is properly cited. 
that PDGF-B is released during platelet degranulation and acts as a paracrine agent $[5,10]$.

With respect to potential coating techniques, PDGFloaded poly(l-lactide) (PLLA) membranes are used to enhance tissue regeneration [11]. Different release kinetics of PDGF from different materials have been investigated [12] and led to many potential uses of coating materials in periodontal and trauma surgery for implant in-growths or acceleration of bone healing $[13,14]$.

AC-100 (Dentonin ${ }^{\mathrm{TM}}$ ) corresponding with the central sequence of human MEPE (matrix extracellular phosphoprotein or OF45: osteoblast/osteocyt factor 45) is a stimulator for new bone formation by increasing the number of osteoblasts. Cleaved from the SIBLING (Small Integrinbinding LIgand, N-linked Glycoprotein) family, MEPE is secreted in the bone during proliferation and early maturation phases by fully differentiated osteoblasts. It is suggested that the osteogenic activity of AC-100 is mediated by activating integrin signalling pathways in osteoblasts [15]. Furthermore, MEPE has been also shown to promote the formation of reparative dentin $[15,16]$.

The thrombin-related peptide TP508 (Chrysalin ${ }^{\mathrm{TM}}$ ) is a synthetic 23-amino acid peptide representing the natural sequence of the receptor-binding domain of human thrombin (prothrombin amino acids 508-530). This peptide was initially identified by its ability to compete with thrombin for binding to a high-affinity thrombin receptor on fibroblasts and to generate receptor occupancy-dependent mitogenic signals. Subsequently, a number of studies demonstrated a potential therapeutic role of TP508 in tissue repair $[17,18]$. In fracture repair, TP508 has been shown to promote angiogenesis and enhance bone strength formation by increased induction of early growth factors and inflammatory mediators [19].

p-15 (Pepgen ${ }^{\mathrm{TM}}$ ) is an FDA-approved, tissue-engineered product that contains anorganic bone mineral (ABM) scaffold and is coated with an active peptide sequence. This peptide surface is derived from the $\alpha 1$ chain of collagen Type I and promotes the attachment and proliferation of fibroblasts and osteoblasts to ABM [20,21].

The aim of this study was to test the hypothesis that the combined use of PDGF-BB with synthetic peptides could result in an increase in proliferation and calcification of osteoblast-like cells. This was done by comparing the effects of PDGF and the peptides AC-100, TP508 or p-15 singly or combined in osteoblast-like cells stimulation.

\section{Methods}

\section{Isolation of human osteoblast-like cells}

Bone specimens were obtained from femur neck of patients (age 50-80 years) undergoing total hip replacement according to the guidelines of the local Ethics Committee. Primary osteoblast cultures were obtained from bone specimens using a previously described technique
[22] slightly modified for our experiments. Briefly, trabecular bone fragments were cut into pieces, thoroughly rinsed in phosphate buffered saline (PBS) and kept in MEM:HAMS F12 (1:1) (Biowest, Berlin, Germany) medium containing 10\% FCS and antibiotics (100 U penicillin/ml, $100 \mu \mathrm{g}$ streptomycin/ml) (Gibco, Life Technologies). Cultures were initiated in $75-\mathrm{cm}^{2}$ culture flasks (BD Biosciences, Bedford, MA) within $3 \mathrm{~h}$ and incubated at $37^{\circ} \mathrm{C}$ in a humidified atmosphere of $5 \% \mathrm{CO}_{2}$. Culture medium was replaced $3 \times$ weekly. Under these conditions, cells migrated out of the bone-forming a monolayer within 3-4 weeks. Primary cell layers were washed in PBS, detached with trypsin EDTA solution (Biowest, Berlin, Germany) and subcultured once in a 1 to 3 ratio. After growth to confluence, cells were released from culture dish as described above. Cells were either frozen at passage 1 or used for experiments in passage 3. Human recombinant PDGF-BB was obtained from R\&D Systems, Inc., U.S.A, AC-100 from Acologix, Inc., U.S.A. P-15 and TP508 were synthesized by Sigma-Aldrich, Germany.

\section{Stimulation of osteoblast-like cells}

Cells from $\geq 5$ patients were pooled and seeded at a density of $1 \times 10^{4}$ in 24-well tissue culture plates (Falcon, Becton Dickinson Labware, USA) and chamber slides (Nalge Nunc International Corp., USA). Cells were cultured as described above. In order to gain osteoinductivity, the medium was supplemented with L-ascorbic acid-2phosphate $(0.1 \mathrm{mM})$ and $ß$-glycerolphhosphate $(10 \mathrm{mM})$. Stimulation of cultures was done over a period of 2, 5 and 10 days, with the growth factors and peptides listed in Table 1. Cultures without additional growth factors and peptides served as controls.

\section{Proliferation and cell number}

Growth of cultures was determined cytologically by counting proliferating cells using Ki-67 antibody (Dako Cytomation, Hamburg, Germany) and total cells (methyl green stain). Briefly, after removal of the medium, cells were rinsed twice in PBS, fixed with methanol on the chamber slides and treated with blocking serum followed by incubation with Ki-67 antibody according to the manufacturer's specifications. Detection was done using Vector Stain Kit (Vector Laboratories, Burlingame, USA) and counterstained with methyl green (Vector Laboratories, Burlingame USA). Proliferating cells and total cells were counted in 5 different areas within 3 independent experiments

Table 1 Factor concentrations used in the experiments

\begin{tabular}{ll}
\hline AC 100 & $1000 \mu \mathrm{g} / \mathrm{ml}$ \\
p-15 & $1000 \mu \mathrm{g} / \mathrm{ml}$ \\
TP508 & $500 \mu \mathrm{g} / \mathrm{ml}$ \\
PDGF - BB & $10 \mu \mathrm{g} / \mathrm{ml}$ \\
\hline
\end{tabular}


using an Olympus BX51 microscope and Image Pro Plus analysis software (Chromaphor Analysen Technik, Duisburg, Germany).

\section{Calcification}

The degree of mineralization was determined for osteoblast-like cell cultures grown on chamber slides using van Kossa stain. Cells layers were fixed with methanol and incubated in $3 \%$ aqueous silver nitrate (30 min). Samples were then washed with deionized water and excess silver was removed using $5 \%$ aqueous sodium thiosulphate for approximately $5 \mathrm{~min}$. After rinsing in distilled water, the slices were analyzed histomorphologically using the same microscope and software described above. At least 5 areas $(500 \mu \mathrm{m} \times 500 \mu \mathrm{m})$ in 3 independent experiments were analyzed by 2 independent investigators.

\section{Total RNA extraction and cDNA synthesis}

RNA was extracted from cell layers using RNeasy Mini Kit (Qiagen, Hilden, Germany) according to the manufacturer's specifications and quantified spectrometrically. Starting from $1 \mu \mathrm{g}$ RNA, 20- $\mu \mathrm{l}$ cDNA was synthesized using Omniscript reverse transcriptase and oligo-dT primer in presence of dNTP (Qiagen, Hilden, Germany).

\section{Quantitative RT-PCR}

Quantitative reverse transcriptase polymerase chain reactions (RT-PCR) were performed and monitored using an ABI Prism 7700 Sequence Detection System (Applied Biosystems, Rotkreuz, Switzerland). The PCR $2 \times$ master mix was based on AmpliTAQ Gold DNA-Polymerase (Applied Biosystems, Rotkreuz, Switzerland). Genes of interest were analyzed in cDNA samples $(5 \mu \mathrm{l}$ for a total volume of $25 \mu \mathrm{l} /$ reaction) using the standard curve method (Perkin Elmer User Bulletin N. 2). Probes were labeled with 6-carboxy fluorescein (FAM) and TAMRA Cycle temperatures and times were as previously described [23]. Primers and probes for human alkaline phosphatase, collagen I, osteocalcin, and $18 \mathrm{~s}$ rRNA were previously described and purchased from TIB Biomol, Berlin, Germany [24].

\section{Statistical Analysis}

All values are presented as mean \pm standard errors (SE). Statistics were assessed within each of the 3 independent experiments using Mann-Whitney U-test with $\mathrm{p}<0.05$ considered to be significant.

\section{Results}

\section{Proliferation}

For the Ki-67 -indexed proliferation, combinations and single factors induced a constant cell proliferation in comparison to the control. Proliferation was significant for all peptides with PDGF $(\mathrm{p}<0.05)$ during the whole time course (Figures 1, 2 and 3).
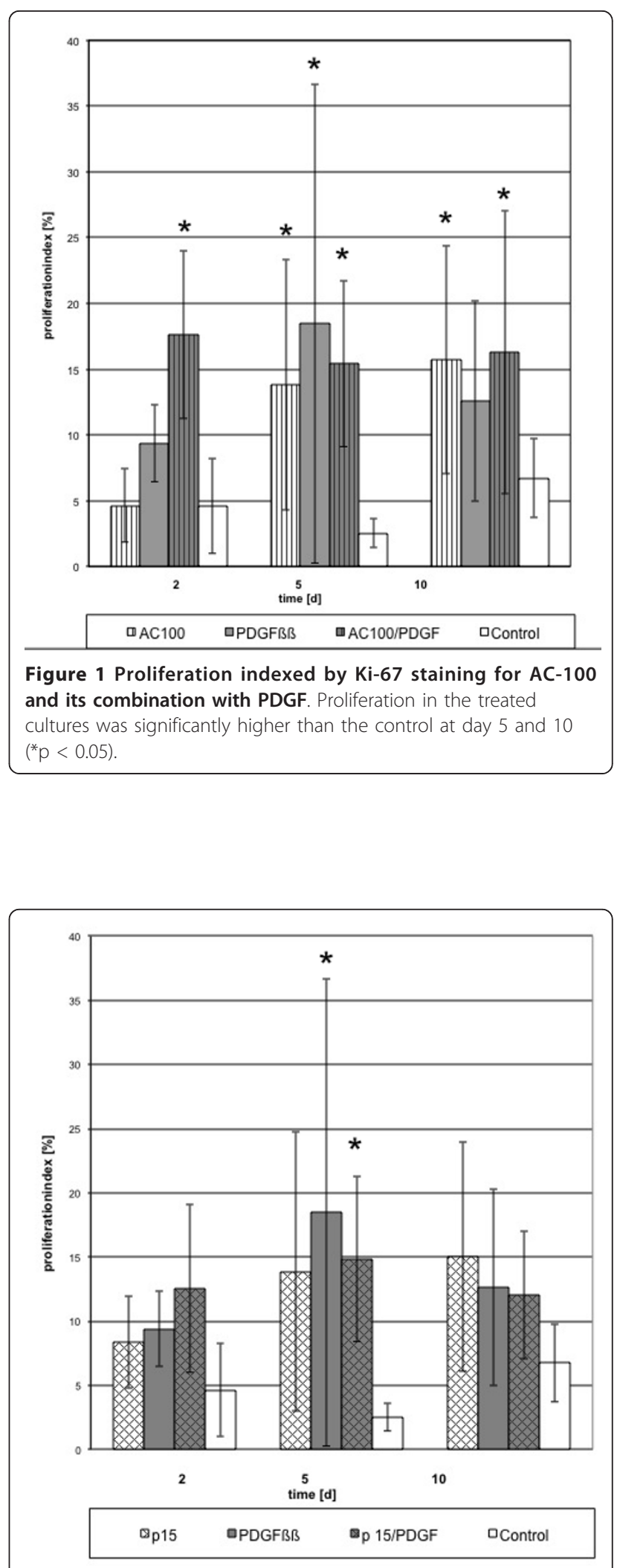

Figure 2 Proliferation indexed by Ki-67 staining for p-15 and its combination with PDGF. Proliferation in the treated cultures was significantly higher than the control at day $5\left({ }^{*} p<0.05\right)$. 


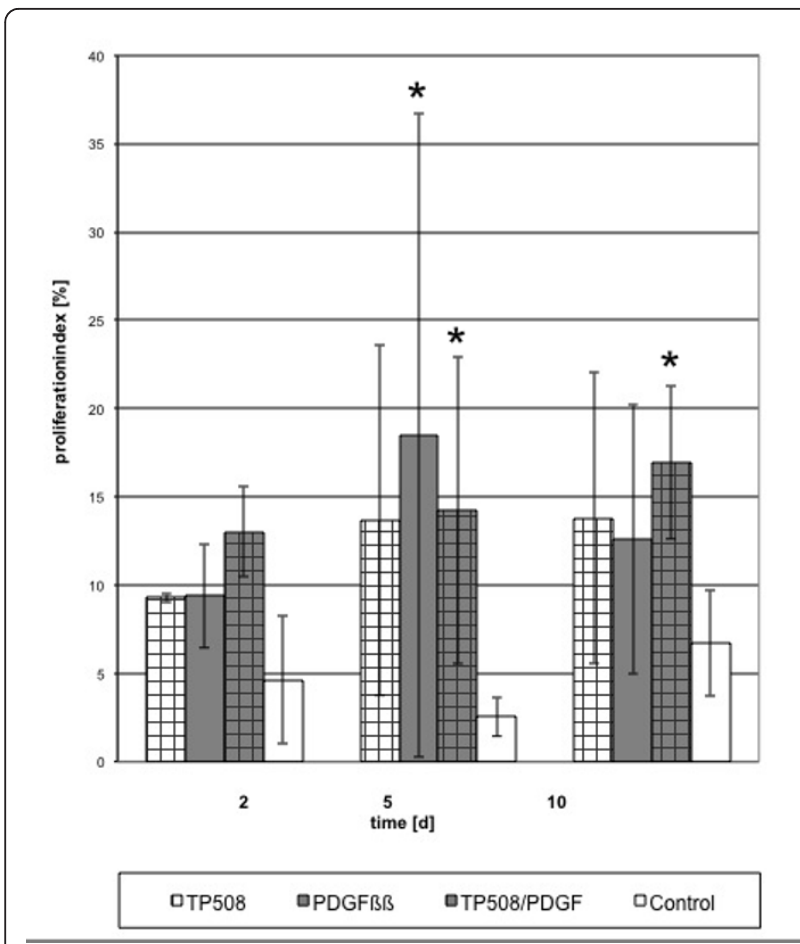

Figure 3 Proliferation indexed by Ki-67 staining for TP508 and its combination with PDGF. Proliferation in the treated cultures was significantly higher than the control at day $5\left({ }^{*} p<0.05\right)$.

Figures 4 and 5 show the absolute cell counts calculated from the mean values obtained from 3 independent cultures treated with peptides and PDGF.

In comparison to control, the addition of either PDGF or peptides or their combinations resulted in a significant increase of proliferating cells $(\mathrm{p}<0.05)$, especially in the

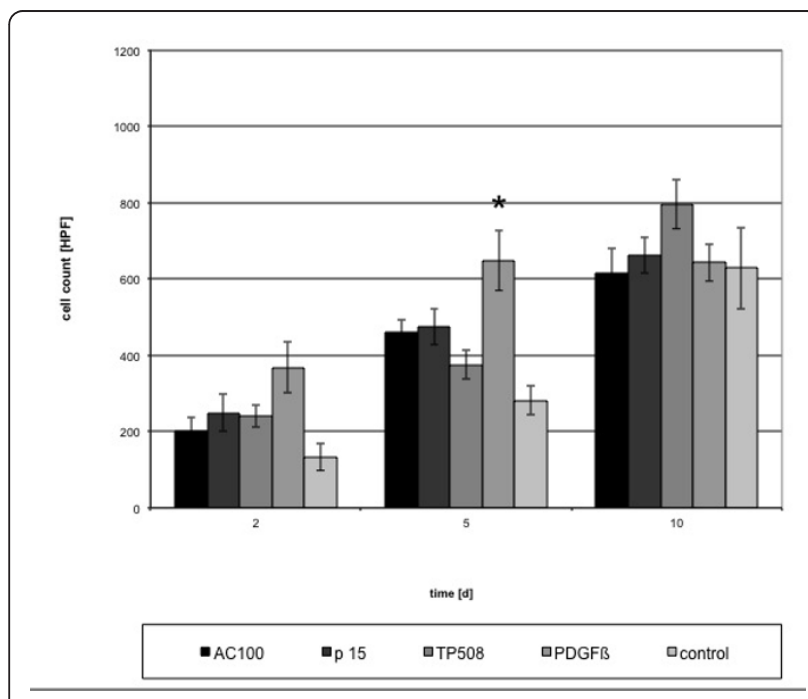

Figure 4 Absolute cell counts in experiments with single factors. (HPF $=$ high power field) $\left(^{*} p<0,001\right)$.

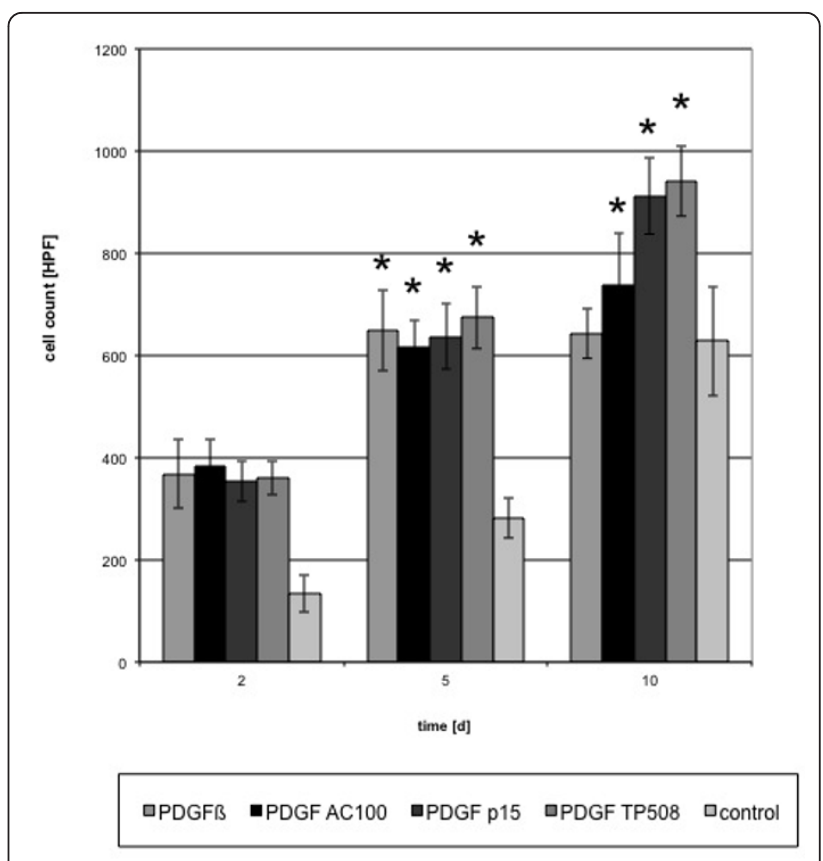

Figure 5 Absolute cell counts in experiments with combined factors; (HPF = high power field) ( $\left.{ }^{*} p<0,001\right)$.

first 5 days. A significant increase $(\mathrm{p}<0.05)$ was reached at day 10 using PDGF/TP508, PDGF/AC-100 combinations. No significant increase $(p>0.05)$ was observed when proliferation was compared to cultures induced by either of the single factors.

\section{Calcification}

Although the degree of calcification differed between the single series, an increase of calcification relative to controls was observed in cultures treated with the 3 PDGF combinations. We found that the onset of calcification in osteoblasts occurred earlier and was more distinct compared to the control. This increase in calcification was significantly higher $(\mathrm{p}<0.05)$ relative to the control for PDGF/p-15 and PDGF/AC-100 at days 5 and 10 (Figures 6, 7 and 8).

\section{Gene expression experiments Alkaline phosphatase}

Alkaline phosphatase as a marker of bone formation was expressed in osteoblast-like cells during long-term cultivation, typically showing a maximum of expression at day 5. In our experiments, the expression was unaffected or diminished (not significant at $\mathrm{p}>0.05$ ) by addition of AC-100, TP508 and p-15 as well as their combinations with PDGF.

\section{Collagen I}

With the exception of PDGF treatment, no increase in collagen I expression was observed. A trend of reduced collagen I expression was found, especially with PDGF/ 

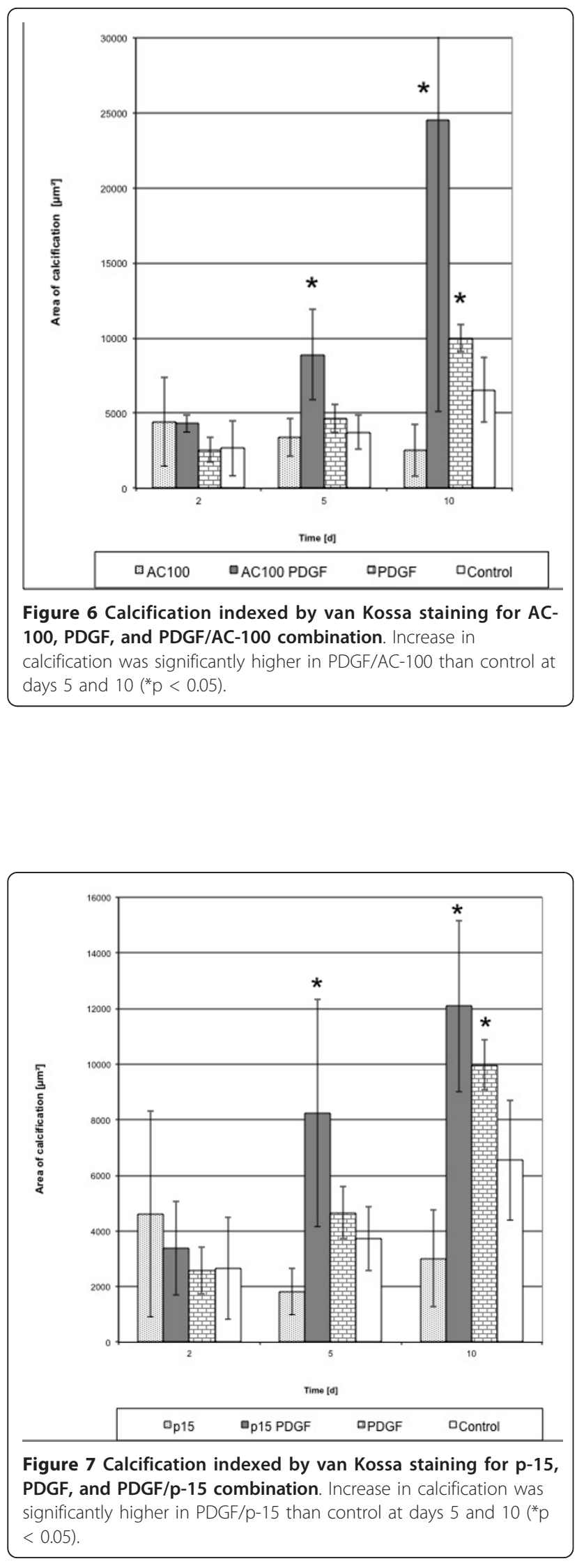

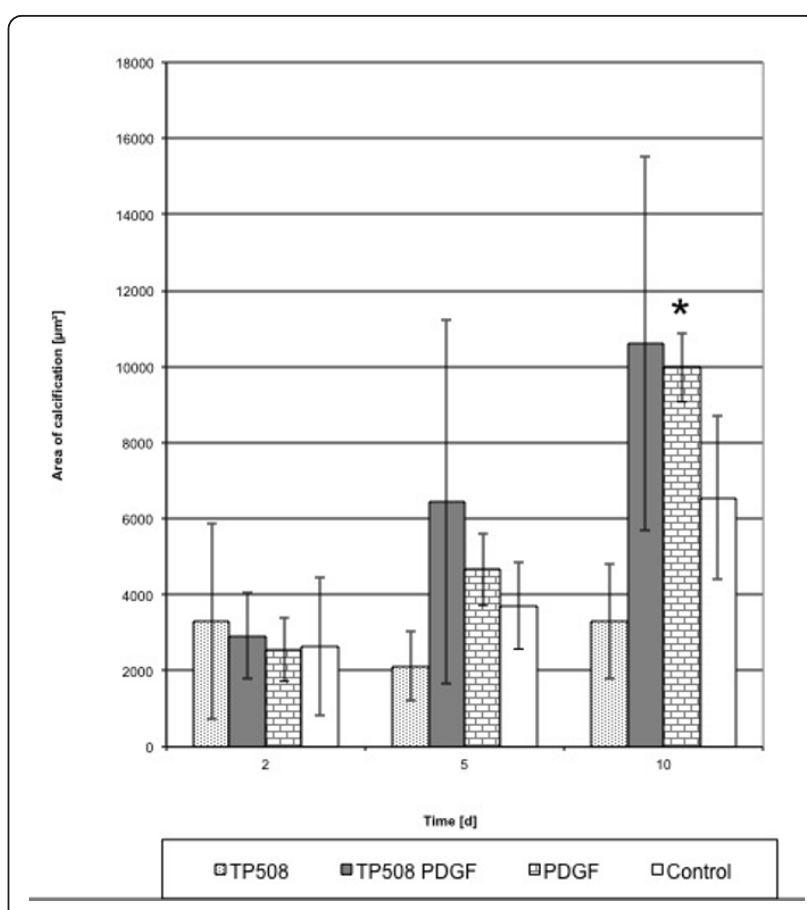

Figure 8 Calcification indexed by van Kossa staining for TP508, PDGF, and PDGF/TP508 combination. Increase in calcification was not significantly higher in PDGF/TP508 than control at days 5 and $10\left({ }^{*} \mathrm{p}<0.05\right)$.

AC-100 and PDGF/p-15 combinations but this did not reach statistical significance $(\mathrm{p}>0.05)$.

\section{Osteocalcin}

Long-term culture of osteoblasts resulted in a timedependent increase of osteocalcin gene expression, reaching a maximum 10 days after inoculation. In the presence of p-15 and AC-100 as well as PDGF, a 2-fold increase of osteocalcin gene expression was observed in at least in 2 of the 3 independent experiments at 2 and 10 days after inoculation. The combined use of PDGF with either of the matrix-derived peptides had similar effects on the osteocalcin expression but a 2 -fold increase in osteocalcin gene expression was observed only in minor experiments. Over all, there were no significant differences between the different cell culture treatments $(\mathrm{p}>0.05)$.

\section{Discussion}

This study investigated the effects of stimulation with PDGF-BB combined with synthetic peptides on osteoblast-like cells, with respect to cell proliferation, calcification and gene expression. In particular, the cooperative action of PDGF with synthetic matrixderived peptides was explored.

In our experiments, stimulation with peptides exhibited in a significant proliferative effect on the osteoblastlike cells, especially within the early phase of cultivation. 
The combination of peptides with PDGF resulted in the same proliferative effect, but showed no significant differences when compared to the single substances. The thrombin fragment TP508 enhances proliferation and differentiation and induces chemotaxis in human osteoblasts [25]. AC-100 a synthetic fragment of MEPE, and $\mathrm{p}-15$, the 15 amino acid residue related to the biological active domain or collagen, are known to stimulate proliferation and differentiation of early uncommitted osteoblast precursors [26] and dental pulp stem cells [27]. In literature, AC-100 and TP508 have more proliferative and differentiating effects whereas $\mathrm{p}-15$ is more of a proliferative factor. Our experiments confirm these studies.

Focusing on the differentiation of the osteoblast-like cells, we found that the onset of calcification in osteoblasts under combined stimulation occurred earlier and was significantly higher compared to the corresponding control or PDGF stimulation alone. This calcification was accompanied with an alteration in the gene expression of the matrix components collagen I and osteocalcin in osteoblasts. This may be indicative of a cooperative effect between extracellular matrix (ECM) molecules, peptides and PDGF-BB. It is consistent with observations in other cell types where such effects between integrin, adhesions, growth factors and PDGF have been elucidated [28,29]. Bartold et al. [30] reported that PDGF-BB stimulated the synthesis of proteoglycans. Proteoglycan synthesis precedes collagen synthesis and cell surface proteoglycans can bind a number of growth or cell motility factors [30-32]. The newly formed ECM is an important regulator of cell migration und differentiation. Therefore, the effect of PDGF-BB on collagen synthesis may play an important role in the calcification together with the effect on proteoglycan synthesis. It is reported that the extracellular signal-regulated kinase (ERK) is activated and modulated by PDGF $[31,33]$.

Cell migration studies indicated that PDGF stimulates migration, but has no effect on proliferation. These results were not confirmed by our findings. Wildemann et al. [34] also observed no cell migration under PGDF stimulation released from a drug delivery system but reported an increased proliferation of osteoblasts.

Chaudhary et al. [35] reported that PDGF-BB-treated cells showed very low alkaline phosphatase activity, indicating that PDGF-BB is a potent proliferative factor for osteoblasts but not a factor for differentiation and mineralization [36]. These findings were confirmed by Kono et al. who suggested that the ERK pathway activated by PDGF is a negative regulator of matrix mineralization [37].

Our data gave evidence that the interaction between PDGF and the ECM can be stimulated by biologically active peptides.
As PDGF has been identified as a paracrine factor resulting from the fracture hematoma [38], we speculate that combined use of one of the matrix derived peptides with PDGF-BB is a useful tool to enhance fracture healing or promote healing of osteoarthritis defects.

One limitation of the study maybe the possible interactions between serum in the culture medium and the PDGF-peptide combinations that could modify the over all effects. This should be addressed in future studies.

\section{Conclusions}

In conclusion, our findings support the hypothesis that the combined use of PDGF-BB with synthetic peptides could result in an increase in proliferation and calcification of osteoblast-like cell. We suggest based on our findings that the combined stimulation of osteoblasts with synthetic peptides and PDGF could accelerate bone healing through cooperative effects. These effects have a potential clinical application in coating osteosynthesis materials to accelerate bone healing. However, further studies in vitro and in vivo are warranted.

\section{Acknowledgements}

We acknowledge Simone Niehues, assistant medical technician, for help in performing the experiments and Raquel Billiones for writing assistance, funded by financial support of Synthes $\mathrm{GmbH}$, Switzerland. All mentioned persons permitted this acknowledgment.

\section{Author details}

'Department of Trauma, Hand and Reconstructive Surgery, University Hospital Münster, Germany. ${ }^{2}$ Department of Orthopedics, University Hospital Marburg, Germany. ${ }^{3}$ Institute of Musculoskeletal Research, University Hospital Münster, Germany.

\section{Authors' contributions}

All authors contributed to this study. TV made substantial contribution in conception and design of the study, participated in carrying out the experiments, he drafted the manuscript, JRJP carried out the experiments and made the statistical analysis, RH and TP revised critically the manuscript, MJR participate in the design and coordination of the study and gave substantial intellectual support. SO drafted the manuscript, performed the statistical analysis and gave substantial intellectual support. All authors read and approved the final manuscript.

\section{Competing interests}

The authors disclose financial support for this study by Synthes $\mathrm{GmbH}$, Switzerland. The study was performed in order to identify new factors for a potential support of fracture healing. In detail financial support was given for a assistant medical technician and the biochemical factors used in the study.

Received: 11 July 2011 Accepted: 21 November 2011

Published: 21 November 2011

\section{References}

1. Beck LS, Wong RL, DeGuzman L, Lee WP, Ongpipattanakul B, Nguyen TH: Combination of bone marrow and TGF-beta1 augment the healing of critical-sized bone defects. J Pharm Sci 1998, 87(11):1379-1386.

2. Bostrom M, Lane JM, Tomin E, Browne M, Berberian W, Turek T, Smith J, Wozney J, Schildhauer T: Use of bone morphogenetic protein-2 in the rabbit ulnar nonunion model. Clin Orthop Relat Res 1996, , 327 : 272-282.

3. Laflamme C, Rouabhia M: Effect of BMP-2 and BMP-7 homodimers and a mixture of BMP-2/BMP-7 homodimers on osteoblast adhesion and 
growth following culture on a collagen scaffold. Biomed Mater 2008, 3(1):015008.

4. Liao J-C, Tzeng S-T, Keorochana G, Lee K-B, Johnson JS, Morishita Y, Murray SS, Wang JC: Enhancement of recombinant human BMP-7 bone formation with bmp binding peptide in a rodent femoral defect model. J Orthop Res 2011, 29(5):753-759.

5. Canalis E, McCarthy T, Centrella M: Growth factors and the regulation of bone remodeling. J Clin Invest 1988, 81(2):277-281.

6. Ranly D, McMillan J, Keller T, Lohmann C, Meunch T, Cochran D, Schwartz Z, Boyan B: Platelet-derived growth factor inhibits demineralized bone matrix-induced intramuscular cartilage and bone formation - A study of immunocompromised mice. J Bone Joint Surg Am 2005, 87A(9):2052-2064.

7. Vanhaesebroeck B, Claesson-Welsh L: The PI 3-kinase isoforms p110(alpha) and p110(beta) have differential roles in PDGF- and insulin-mediated signaling. J Cell Sci 2000, 113(Pt 2):207-14

8. Barnes GL, Kostenuik PJ, Gerstenfeld LC, Einhorn TA: Growth Factor Regulation of Fracture Repair. J Bone Miner Res 1999, 14(11):1805-1815

9. Mohan S: Bone growth factors. Clin Orthop Relat Res 1991, , 263: 30-48.

10. Siegbahn A, Hammacher A, Westermark B, Heldin CH: Differential effects of the various isoforms of platelet-derived growth factor on chemotaxis of fibroblasts, monocytes, and granulocytes. J Clin Invest 1990, 85(3):916-920.

11. Park YJ, Lee YM, Lee JY, Seol YJ, Chung CP, Lee SJ: Controlled release of platelet-derived growth factor-BB from chondroitin sulfate-chitosan sponge for guided bone regeneration. J Control Release 2000, 67(23):385-394.

12. Walsh WR, Kim HD, Jong YS, Valentini RF: Controlled release of plateletderived growth factor using ethylene vinyl acetate copolymer (EVAC) coated on stainless-steel wires. Biomaterials 1995, 16(17):1319-1325.

13. Schmidmaier G, Lucke M, Schwabe P, Raschke M, Haas NP, Wildemann B: Collective review: bioactive implants coated with poly(D, L-lactide) and growth factors IGF-I, TGF-beta1, or BMP-2 for stimulation of fracture healing. J Long Term Eff Med Implants 2006, 16(1):61-69.

14. Schmidmaier G, Wildemann B, Bail H, Lucke M, Fuchs T, Stemberger A, Flyvbjerg A, Haas NP, Raschke M: Local application of growth factors (insulin-like growth factor-1 and transforming growth factor-beta1) from a biodegradable poly(D,L-lactide) coating of osteosynthetic implants accelerates fracture healing in rats. Bone 2001, 28(4):341-350.

15. Hayashibara T, Hiraga T, Yi B, Nomizu M, Kumagai Y, Nishimura R, Yoneda T: A synthetic peptide fragment of human MEPE stimulates new bone formation in vitro and in vivo. J Bone Miner Res 2004, 19(3):455-462.

16. Six N, Septier D, Chaussain-Miller C, Blacher R, DenBesten P, Goldberg M: Dentonin, a MEPE fragment, initiates pulp-healing response to injury. J Dent Res 2007, 86(8):780-785.

17. Wang Y, Wan C, Szöke G, Ryaby JT, Li G: Local injection of thrombinrelated peptide (TP508) in PPF/PLGA microparticles-enhanced bone formation during distraction osteogenesis. J Orthop Res 2008, 26(4):539-546.

18. Hanratty BM, Ryaby JT, Pan X-H, Li G: Thrombin related peptide TP508 promoted fracture repair in a mouse high energy fracture model. $J$ Orthop Surg Res 2009, 4:1.

19. Wang H, Li X, Tomin E, Doty SB, Lane JM, Carney DH, Ryaby JT: Thrombin peptide (TP508) promotes fracture repair by up-regulating inflammatory mediators, early growth factors, and increasing angiogenesis. J Orthop Res 2005, 23(3):671-679.

20. Qian JJ, Bhatnagar RS: Enhanced cell attachment to anorganic bone mineral in the presence of a synthetic peptide related to collagen. $J$ Biomed Mater Res 1996, 31(4):545-54.

21. Nguyen H, Qian JJ, Bhatnagar RS, Li S: Enhanced cell attachment and osteoblastic activity by P-15 peptide-coated matrix in hydrogels. Biochem Biophys Res Commun 2003, 311(1):179-86.

22. Siggelkow H, Niedhart C, Kurre W, Ihbe A, Schulz A, Atkinson MJ, Hüfner M: In vitro differentiation potential of a new human osteosarcoma cell line (HOS 58). Differentiation 1998, 63(2):81-91.

23. Martin I, Jakob M, Schäfer D, Dick W, Spagnoli G, Heberer M: Quantitative analysis of gene expression in human articular cartilage from normal and osteoarthritic joints. Osteoarthritis Cartilage 2001, 9(2):112-8.

24. Frank O, Heim M, Jakob M, Barbero A, Schäfer D, Bendik I, Dick W, Heberer M, Martin I: Real-time quantitative RT-PCR analysis of human bone marrow stromal cells during osteogenic differentiation in vitro. J Cell Biochem 2002, 85(4):737-46.

25. Li G, Cui Y, Mcllmurray L, Allen WE, Wang H: rhBMP-2, rhVEGF(165), rhPTN and thrombin-related peptide, TP508 induce chemotaxis of human osteoblasts and microvascular endothelial cells. J Orthop Res 2005, 23(3):680-685.

26. Kübler A, Neugebauer J, Oh J-H, Scheer M, Zöller JE: Growth and proliferation of human osteoblasts on different bone graft substitutes: an in vitro study. Implant Dent 2004, 13(2):171-179.

27. Liu H, Li W, Gao C, Kumagai Y, Blacher RW, DenBesten PK: Dentonin, a fragment of MEPE, enhanced dental pulp stem cell proliferation. J Dent Res 2004, 83(6):496-499.

28. Miyamoto S, Teramoto H, Gutkind JS, Yamada KM: Integrins can collaborate with growth factors for phosphorylation of receptor tyrosine kinases and MAP kinase activation: roles of integrin aggregation and occupancy of receptors. J Cell Biol 1996, 135(6 Pt 1):1633-1642.

29. Baron W, Shattil SJ, ffrench-Constant C: The oligodendrocyte precursor mitogen PDGF stimulates proliferation by activation of alpha(v)beta3 integrins. EMBO J 2002, 21(8):1957-1966.

30. Bartold PM, Raben A: Growth factor modulation of fibroblasts in simulated wound healing. J Periodont Res 1996, 31(3):205-216.

31. Getachew R, Ballinger ML, Burch ML, Reid JJ, Khachigian LM, Wight TN, Little PJ, Osman N: PDGF beta-receptor kinase activity and ERK1/2 mediate glycosaminoglycan elongation on biglycan and increases binding to LDL. Endocrinology 2010, 151(9):4356-4367.

32. Wight $\mathrm{T}$, Kinsella $\mathrm{M}$ : The role of proteoglycans in cell adhesion, migration and proliferation. Current opinion in cell biology. Curr Opin Cell Biol 1992, 4(5):793-801.

33. Kim SJ, Kim SY, Kwon CH, Kim YK: Differential effect of FGF and PDGF on cell proliferation and migration in osteoblastic cells. Growth Factors 2007, 25(2):77-86.

34. Wildemann B, Burkhardt N, Luebberstedt M, Vordemvenne T, Schmidmaier G: Proliferating and differentiating effects of three different growth factors on pluripotent mesenchymal cells and osteoblast like cells. J Orthop Surg Res 2007, 2:27.

35. Chaudhary LR, Hofmeister AM, Hruska KA: Differential growth factor control of bone formation through osteoprogenitor differentiation. Bone 2004, 34(3):402-411.

36. Yu X, Hsieh SC, Bao W, Graves DT: Temporal expression of PDGF receptors and PDGF regulatory effects on osteoblastic cells in mineralizing cultures. Am J Physiol 1997, 272(5 Pt 1):C1709-16.

37. Kono S-J, Oshima Y, Hoshi K, Bonewald LF, Oda H, Nakamura K, Kawaguchi $H$, Tanaka S: ERK pathways negatively regulate matrix mineralization. Bone 2007, 40(1):68-74.

38. Zhang L, Leeman E, Carnes DC, Graves DT: Human osteoblasts synthesize and respond to platelet-derived growth factor. Am J Physiol 1991, 261(2 Pt 1):C348-54.

\section{Pre-publication history}

The pre-publication history for this paper can be accessed here: http://www.biomedcentral.com/1471-2474/12/263/prepub

doi:10.1186/1471-2474-12-263

Cite this article as: Vordemvenne et al: Cooperative effects in differentiation and proliferation between PDGF-BB and matrix derived synthetic peptides in human osteoblasts. BMC Musculoskeletal Disorders 2011 12:263. 